\title{
The advantages of combining 3D printing with turning process. Case study
}

\author{
Dan Claudiu Negrău ${ }^{1 *}$ Gavril Grebenisan ${ }^{2}$ Ion Cosmin Gherghea ${ }^{2}$, Daniel Anton ${ }^{2}$ \\ ${ }^{1}$ University of Oradea, Department of Engineering and Management, Universităţii 1, Oradea, \\ Romania \\ ${ }^{2}$ University of Oradea, Department of Industrial Engineering, Universităţii 1, Oradea, Romania
}

\begin{abstract}
The paper presents a case study which the additive manufacturing technology is combined with finishing process by cutting operations (turning) for manufacturing a part. The part was manufactured through additive manufacturing, using a $3 \mathrm{D}$ printer and the and the finishing process is performed by a lathe, resulting in technological properties and the corresponding dimensional accuracy. The research paper also contains the analysis of the roughness and other properties of the material from which the final part will be made. The manufactured part will be used as a support for the blades of a fan during the assembly process, which emphasizes that a part obtained by additive manufacturing (3D printing) can replace a part obtained by casting or fabrication by total cutting. In conclusion, obtaining the manufactured part by combining the two manufacturing processes, the lead time and the production cost has been significantly reduced, while the quality of the obtained product also increased, obtaining a very good roughness.
\end{abstract}

\section{Introduction}

A new industrial revolution is the implementation of additive manufacturing (AM) [1], designed to replace totally or partially technologies for manufacturing processing and subassembly in all industrial fields.

Industrial analysts are considering $\mathrm{PA}[2]$ as new rights or technologies mentioned to currently influence and change industrial technologies. PA is often referred to as printing (3D printing), which may be similar to laser printing (fig. 1). PA builds solid objects by superimposing material layers; each layer is drawn by the computer [3 - 4].

Corresponding author: dan.negrau@yahoo.com 


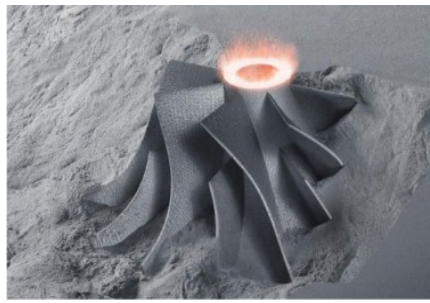

Fig. 1. Laser fusion of metals [2]

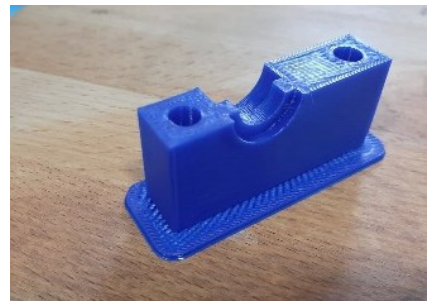

Fig. 2. Fused deposition modeling FDM [3]

In a product development context, the term rapid prototyping has been widely used and describes technologies that have developed physical prototypes directly from the digital-3D model to finished parts [5],[6].

One of the problems with 3D printing [7] is that the printed material, both plastic and metal, has a rough surface as well as inclusions for which it is necessary to finish subsequently by cutting operations. Thus the new machines that are now emerging on the market are hybrid CNC machines [8], such a CNC machine (fig. 3) having a very high accuracy but also a fairly high price [9].

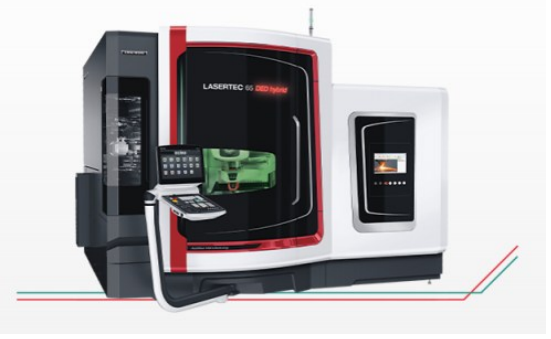

Fig. 3. LASERTEC 65 DED hybrid [9]

Although the abovementioned impediments such as rough surface, inclusions and other such problems occur, they can be eliminated by different methods [10],[11], [12]and, as a result of removing or reducing these impediments, the part will correspond in dimensional and qualitative terms [13].

\section{Functional role of the part. Part material. Tests to identify the printing material}

The part called "fan positioning device", shown in fig.4, is a part for use in industrial engineering and has a functional role in positioning the propeller (fig. 5) of a fan to assemble it together with components such as magnet, stator, and electronics components.

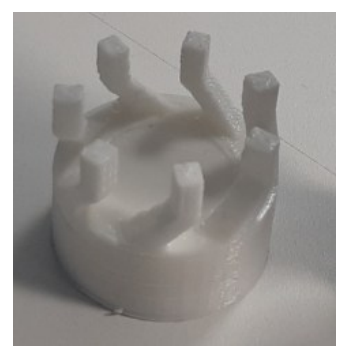

Fig. 4. Fan positioning device

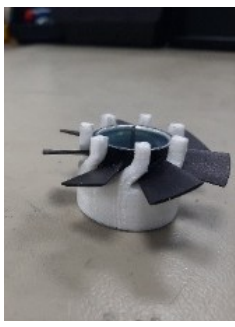

Fig. 5. Propeller fixed in the device 
The material from which the original part was made is POM-C (polyamide), material with good characteristics and mechanical properties. It has been choose as the starting material of the POM-C part and because it is a plastic material, which prevents the fan from scratching, thus the resulting fans correspond esthetically to the satisfactory level. The problem with this positioner being constructed of plastic material is that the toothed zone of the positioner device, if struck by another object, is broken and thus not functional (fig.6). The remedy, operational and efficient, i.e. restoration of the positioning device teeth (shown in fig. 5), which was accidentally broken after several solutions were used to repair/replace it, was the use of $3 \mathrm{D}$ printing technology.

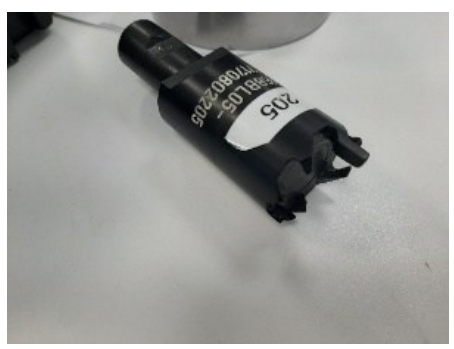

Fig. 6. The original positioner device-faulty

In the first phase, we requested its manufacture by collaborating companies, only that the delivery time was 5 weeks and in addition, the price of such a positioner reaching over 200 Euro. Given this impediment with the delivery time of this part, we resorted to 3D printing of it using a printer with cartesian displacement system (fig. 7), and as a safety measure to confirm that the PLA material [14] from which it will be made by 3D printing corresponds to the required fixing standards, samples of PLA material were printed (fig. 8), which were subsequently analyzed using a Nano indenter (fig. 9) provided by the University of Oradea.

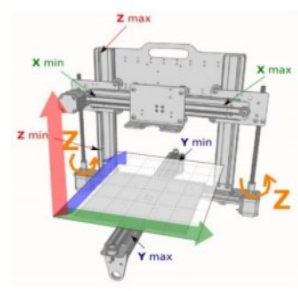

Fig. 7. 3D printer cartesian System

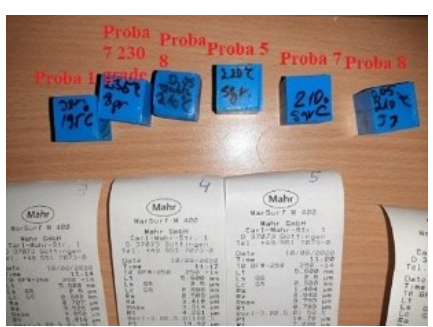

Fig. 8. Samples of PLA material

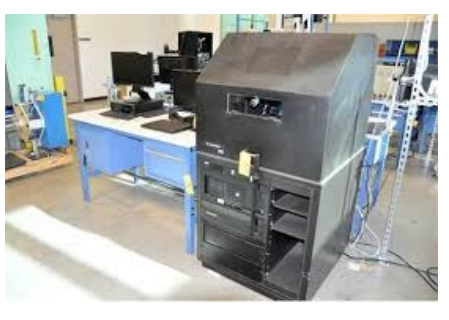

Fig. 9. Nano-indenter G200

Also, knowing that the surface obtained by printing will have an approximate roughness $\mathrm{Ra}=20$, the samples were milling using a Mini Mill $2 \mathrm{CNC}$ machine (fig. 10), and following the tests to verify the mechanical properties (table 1) and those of roughness presented in fig. 11, it was concluded that using PLA to print the fan positioner and subsequently apply the cutting operations, it will meet all operating requirements. 


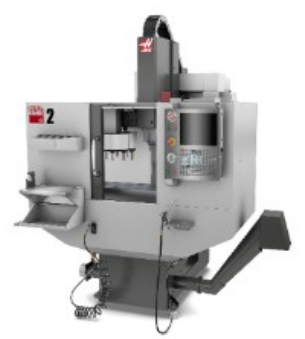

Fig. 10. CNC Haas Mini-Mill2

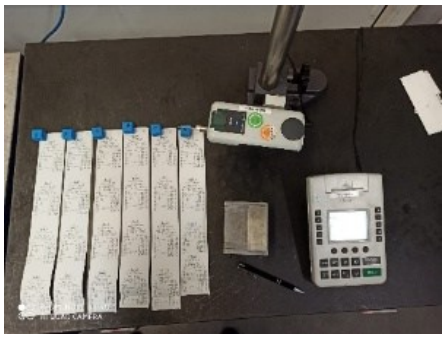

Fig. 11. The roughness of the analyzed samples

Following these studies, tables with the values of cube samples with the size of 20x20x20 mm were prepared. Therefore, the roughness of the parts was determined for several print settings, including the temperature which was the most important setting, starting at $195{ }^{\circ} \mathrm{C}$, the layer being identical for all prints of $0.3 \mathrm{~mm}$, the printing temperature gradually increasing. For each work piece, the inside fill of the work piece is used, also called infill, as a percentage of $100 \%$, the print speed values for nozzle of $0.4 \mathrm{~mm}$ have been set to $60 \mathrm{~mm} / \mathrm{s}$ on the $\mathrm{x}, \mathrm{y}$. On each work piece, the function outer wall with 2 layers of $0.4 \mathrm{~mm}$ each was used, which resulted in an extra filament addition of $\sim 0.1 \mathrm{~mm}$ on the work piece, as the outline first gave the work piece a break during printing, this helped us to trim the work piece and bring it to the desired value. The flow of the filament is also determined by the flow of air dissipated to the last layer deposited, this air flow determines the flow of the filament, because if the fan is at maximum power, it will cool the nozzle enough to cause the filament to harden before depositing on the bed printer or the last printed layer.

For the detailed analysis of the samples, the parts with the printing temperature with values of $195,210,220,235^{\circ} \mathrm{C}$ were chosen due to the fact that they represented the best values from a mechanical point of view and in table 2 are presented the roughness values according to the printing parameters described above of the four samples. Following the indentation [15] of 4 samples, each sample being indented 72 times, averaging the 72 indentations, or the following values were obtained regarding the modulus of elasticity, hardness and rigidity of the samples (table 1), and in table 2 and 3 is specified the technological parameters of the samples.

Table 1. Mechanical and technological properties of samples after indentation

\begin{tabular}{|c|c|c|c|c|c|}
\hline Nr sample & $\begin{array}{c}\text { Recommended } \\
\text { temperature } \\
{\left[{ }^{\circ} \mathrm{C}\right]}\end{array}$ & $\begin{array}{c}\text { Printing } \\
\text { temperature } \\
{\left[{ }^{\circ} \mathrm{C}\right]}\end{array}$ & $\begin{array}{c}\text { Hardness } \\
{[\mathrm{GPa}]}\end{array}$ & $\begin{array}{c}\text { Rigidity } \\
{[\mathrm{N} / \mathrm{m}]}\end{array}$ & $\begin{array}{c}\text { Youngmodul } \\
\mathrm{e}[\mathrm{GPa}]\end{array}$ \\
\hline Sample 1 & $205-220$ & 195 & 0.1 & 68.852 & 5.5 \\
\hline Sample 5 & $205-220$ & 210 & 0.12 & 71.05 & 5 \\
\hline Sample 4 & $205-220$ & 220 & 0.13 & 72.12 & 4.9 \\
\hline Sample 2 & $205-220$ & 230 & 0.11 & 70.159 & 5.1 \\
\hline
\end{tabular}

Table 2. Roughness Ra values depending on the printing parameters

\begin{tabular}{|c|c|c|c|l|l|}
\hline $\begin{array}{c}\mathrm{Nr} \\
\mathrm{crt}\end{array}$ & $\begin{array}{c}\text { Number } \\
\text { sample }\end{array}$ & $\begin{array}{c}\text { Temperature } \\
{\left[{ }^{\circ} \mathrm{C}\right]}\end{array}$ & $\begin{array}{c}\text { Roughness } \\
\mathrm{Ra}\end{array}$ & & \\
\hline & & & $\begin{array}{c}\text { Upper } \\
\text { printing } \\
\text { surface }\end{array}$ & Printing area & \\
& & & & & \\
\hline
\end{tabular}




\begin{tabular}{|c|c|c|c|c|c|} 
& & & & $\begin{array}{c}\text { On the along of } \\
\text { print direction }\end{array}$ & $\begin{array}{c}\text { On the transversal } \\
\text { direction }\end{array}$ \\
\hline 1 & 2 & 230 & 4.973 & 0.600 & 18.670 \\
\hline 2 & 4 & 220 & 0.509 & 0.629 & 18.850 \\
\hline 3 & 5 & 210 & 1.484 & 0.406 & 20.560 \\
\hline 4 & 1 & 195 & 0.648 & 1.191 & 17.600 \\
\hline
\end{tabular}

Table 3. RoughnessRz values depending on the printing parameters

\begin{tabular}{|c|c|c|c|c|c|}
\hline Nr crt & & $\begin{array}{c}\text { Roughness } \\
\text { Rz }\end{array}$ & & & The milling surface \\
\hline & The milling & $\begin{array}{c}\text { Upper } \\
\text { printing } \\
\text { surface }\end{array}$ & Printing area & & \\
\hline & & $\begin{array}{c}\text { On the along } \\
\text { of print } \\
\text { direction }\end{array}$ & $\begin{array}{c}\text { On the } \\
\text { transversal } \\
\text { direction }\end{array}$ & \\
\hline 1 & 0.678 & 23.540 & 3.056 & 76.060 & 5.901 \\
\hline 2 & 1.340 & 3.410 & 2.745 & 81.400 & 12.260 \\
\hline 3 & 1.610 & 6.942 & 2.176 & 83.310 & 14.820 \\
\hline 4 & 2.958 & 3.297 & 5.917 & 72.760 & 17.960 \\
\hline
\end{tabular}

Based on table 2 and 3 we drew roughness graphs of the four samples according to the printing plans, respectively the plan that was milled (fig. 12).

Ra-Rz upper printing surface

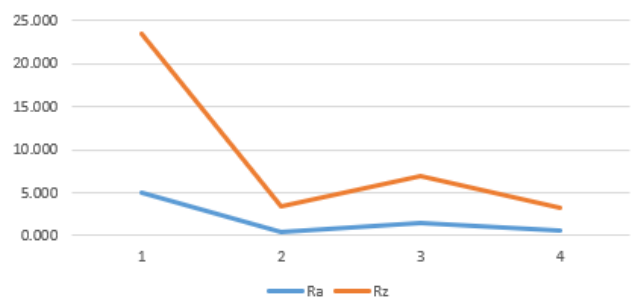

a) Ra-Rz upper printing surface

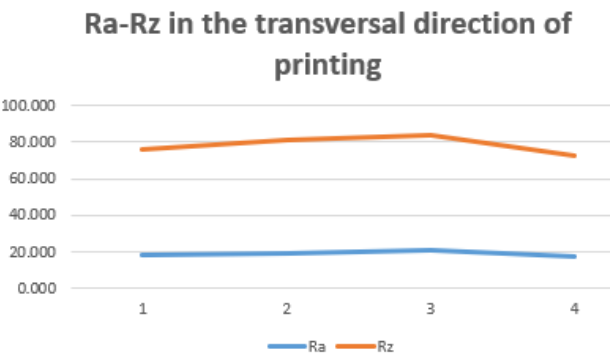

c) Ra-Rz on the transversal direction

\section{$\mathrm{Ra}-\mathrm{Rz}$ in the direction of printing}

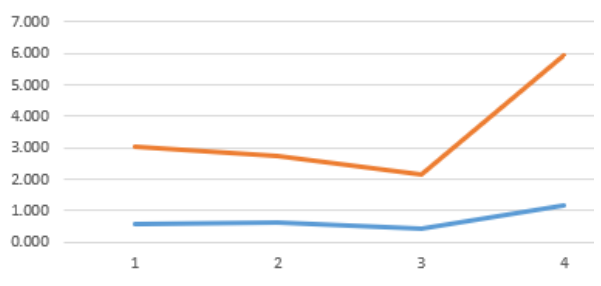

b) Ra-Rz along of print direction Ra-Rz after cuttting operation

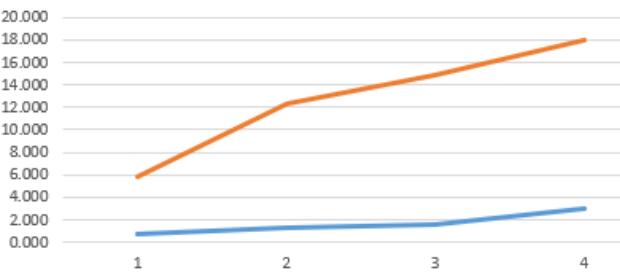

- Ra $-\mathrm{Rz}$

d) Ra-Rz after cutting operation (milling)

Fig. 12.Roughness graphs

According to tables 1,2 and 3, sample no. 4 has the best mechanical and technological properties, and from the point of view of the roughness of the chipped surface it presents $\mathrm{Ra}=1.34 \mu \mathrm{m}$, so that the fan positioner will be printed with the parameters used for printing sample no. 4 and as printing parameters for the device we used the parameters corresponding to sample $4[16]$. 


\section{The manufacturing technology of the part}

Based on the results presented in point 2, we decided to continue the production of the positioner by 3D printing, and thus the first stage represented the 3D modeling of this mark (fig. 13), and then to draw it out (fig. 14), for this using Solid Edge 2021 [17].

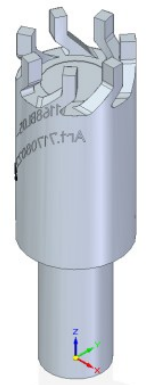

Fig. 13. 3D-model device positioner
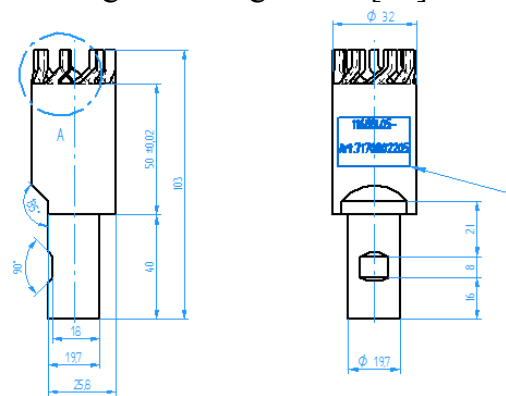

The next step was to print the positioning device (fig. 15), a device that is composed of two distinct areas (tooth area and cylindrical area for fixing it), so in the future will change only the tooth area when it is will break, and the time to solve this problem will be shorter, as well as the stopping time of the car being shorter [18],[19].

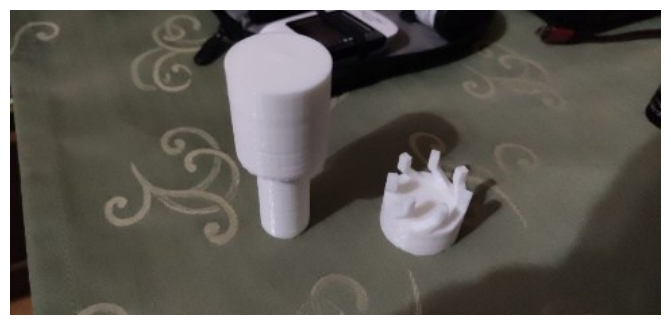

Fig. 15. Device positioner 3 printing

After printing it, in order to be finished we used as a cutting operation the inner turning (fig. 16), turning which is necessary to obtain a roughness $\mathrm{Ra}=3.2$ and the dimension of $\phi 24$, respectively $\phi 19$ (fig. 17) on the different depths.

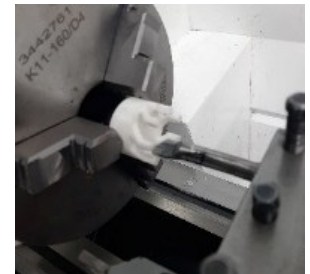

Fig 16. Inner turning

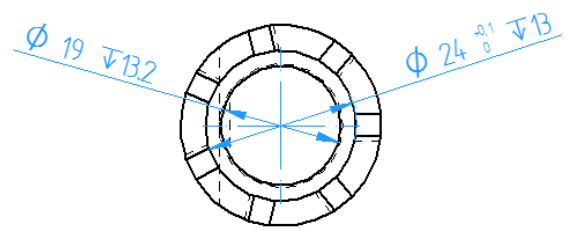

Fig. 17. The internal dimension of device

After completion of the turning operation, the two components of the positioning device were fixed together (fig. 18) so that the device shown in fig. 19 became functional, and in fig. 20 is shown mounted in the equipment in which it operates [3]. 


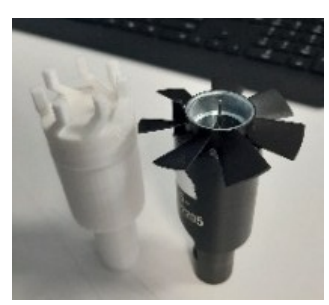

Fig. 18. Positioner device PLA and POM-C

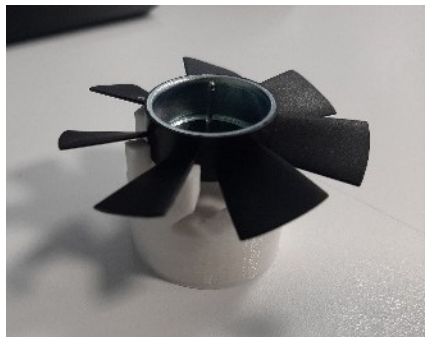

Fig. 19. Positioner device after turning-finished

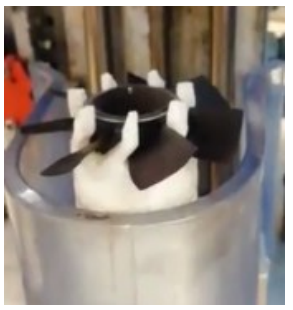

Fig. 20. Positioning device mounted on the equipment

\section{Conclusion}

In conclusion we discover the next benefits:

- the combination of manufacturing by $3 \mathrm{D}$ printing with manufacturing by cutting, leads to the realization of parts with high complexity,

- the quality of the surfaces obtained after the cutting operation has a very good roughness,

- $\quad$ the part was obtained with machines that have a much lower price compared to a 4 5-axis machine or an injection mold,

- the price of the part using 3D printed + turning is about 15 EURO compared to its processing using a CNC milling machine where the price is 250 EUR

The future development:

- printing tests, with speed adjustment depending on the height of the printing layer, temperature adjustment for the optimal printing speed, depending on the flow rate, without having problems with the filament flow

- tensile testing for elasticity, stas models from the module SR EN ISO 527-1: 2020 for printed plastic parts[16]

- $\quad$ printing with different nozzles for different printing heights and observing them under a microscope [20]

- observation of the volumetric deformation on parts with 7 markings (observation steps at traction) [11]

- observation of the deformation phases in perforated parts

- $3 \mathrm{D}$ printing and cutting on the same machine

Published with the support of the University of Oradea because it provided me with scientific resources and with the support of the ID 123008 - POCU/380/6/13 project, - SMARTDOCT Programe de înaltă calitate pentru doctoranzii și cercetătorii postdoctorat ai Universității din Oradea pentru creșterea relevanței cercetării și inovarii în contextul economiei regionale.

\section{References}

1. I. Ebert-Uphoff, C. M., D. W., T. Laliberte, Rapid Prototyping for Robotics, no. July (China, 2005)

2. D. C. Negrau, G. Grebenian, C. Gherghea, "A brief overview of Additive Manufacturing," IOP Conf. Ser. Mater. Sci. Eng., 898, 1 (2020)

3. https://www.ebmpapst.ro/ro/company/company.html [Accessed. 26.04. 2021]

4. V. Shanmugam et al., "Fatigue behaviour of FDM-3D printed polymers, polymeric 
composites and architected cellular materials," Int. J. Fatigue, 143 October (2020)

5. L. B. N. S. and J. M. Usher, Laser-Based Additive Manufacturing of Metal Parts. (ISBN-13: 978-1-4987-3999-3, 2018)

6. N. Qaud, Additive manufacturing technologies at Sulzer, 100,2 (2018)

7. A. van Wijk, I. van Wijk, $3 D$ printing with biomaterials: Towards a sustainable and circular economy, no. January (2015)

8. K. P. Karunakaran, A. Bernard, S. Suryakumar, L. Dembinski, G. Taillandier, "Rapid manufacturing of metallic objects," Rapid Prototyp. J., 18, 4 (2012)

9. https://en.dmgmori.com/products/machines/additive-manufacturing/powdernozzle/lasertec-65-ded-hybrid [Accessed 26.04.2021]

10. https://oxmet-technologies.com/ [Accessed 26.04.2021]

11. S. Singh, A. Rajeshkannan, S. Feroz, A. K. Jeevanantham, "Effect of Normalizing on the Tensile Strength, Shrinkage and Surface Roughness of PLA Plastic," Mater. Today Proc., 24 (2020)

12. A. Kreitcberg, V. Brailovski, S. Turenne, "Effect of heat treatment and hot isostatic pressing on the microstructure and mechanical properties of Inconel 625 alloy processed by laser powder bed fusion," Mater. Sci. Eng. A, 689 (2017)

13. Y. Huang, M. C. L. March, NSF Work. Rep., no. March, pp. 1-26 (2014)

14. https://www.tonerpartner.ro/articole/cum-sa-alegi-filamentele-potrivite-pentruimprimanta-3d-26146ro39018/ [Accessed 20.04.2021]

15. https://matin.gatech.edu/collections/post/67/download/G200_User_Manual_Rev_D .pdf [Accessed 20.04.2021]

16. C. Tang, J. Liu, Y. Yang, Y. Liu, S. Jiang, W. Hao, "Effect of process parameters on mechanical properties of $3 D$ printed PLA lattice structures, "Compos. Part C Open Access, 3, no. September (2020)

17. https://solidedge.siemens.com/en/solutions/products/complete-product-developmentportfolio/whats-new-in-solid-edge-2021/ [Accessed 20.04.2021]..

18. I. C. Gherghea, C. Bungau, D. C. Negrau, "Lead time reduction and increasing productivity by implementing lean manufacturing methods in cnc processing center, 'IOP Conf. Ser. Mater. Sci. Eng., 568,1 (2019)

19. C. I. Indre, F. S. Blaga, C. Micula, D. C. Negrau, "Research in order to decrease the time manufacturing unit using the combined tools," IOP Conf. Ser. Mater. Sci. Eng., 564, 1 (2019)

20. Y. Hu, R. B. Ladani, M. Brandt, Y. Li, A. P. Mouritz, "Carbon fibre damage during $3 D$ printing of polymer matrix laminates using the FDM process, ”Mater. Des., 205 (2021) 